\title{
Punishment effects in rats selectively bred for emotional elimination'
}

DOUGLAS P. FERRARO AND KATHLEEN M. YORK ${ }^{2}$

UNIVERSITY OF NEW MEXICO

Maudsley Reactive and Nonreactive rats were first trained to make a lever press-release response for water reinforcement and then exposed to electric shock punishment. Measures of response rate and response duration showed the reactive strain to be more emotionally responsive to punishment than the nonreactive strain.

The Maudsley Reactive and Nonreactive strains of rats were developed by selectively breeding for high and low defecation in an open-field test of emotionality (Broadhurst, 1960). Subsequent behavioral and physiological comparisons of these strains have suggested that the reactive (high defecating) strain is more emotionally responsive than the nonreactive (low defecating) strain (cf. Eysenck, 1964). The present experiment was designed to extend this line of research using a leverpress punishment procedure. On the basis of the postulated greater emotionality of the reactive strain, it was predicted that the reactive strain would show greater response decrement under punishment than the nonreactive strain. Response duration was used, along with rate of response, as the dependent variable in this experiment since Ferraro \& Hayes (1967) have shown response duration to be a sensitive datum under punishment.

Method

The Ss were four adult male Maudsley Reactive rats and four adult male Maudsley Nonreactive rats obtained from the Iowa State College breeding colony. The Ss were maintained on a $24 \mathrm{~h}$ water deprivation rhythm throughout the experiment.

The experimental chamber was a rat box equipped with a single response lever and liquid dipper programmed to deliver each .02 cc water reinforcement for 3 sec. A shock generator and scrambler was used to deliver .5 sec of ac shock to the chamber floor and response lever. A $10 \mathrm{~g}$ downward force, applied to the response lever through $.5 \mathrm{~cm}$, closed the response microswitch. Response duration was defined as the length of time the response microswitch was held closed. Distributions of response durations were obtained from each rat during every other experimental session. All reinforcements and/or shocks were delivered immediately after the microswitch was opened.

The Ss were trained to make a lever press-release response on a schedule in which every lever-release was positively reinforced. Each $S$ was then exposed for 18 consecutive daily sessions to the regular reinforcement schedule. During this and later phases of the experiment, a session was terminated after
100 reinforcements were delivered or after $15 \mathrm{~min}$ had elapsed. Ss were next given 24 daily sessions in which each lever-release was followed both by reinforcement and by .2 $\mathrm{mA}$ shock punishment. Shock intensity was reduced to $0 \mathrm{~mA}$ for the next 12 sessions, then increased to $.3 \mathrm{~mA}$ for the succeeding six sessions and, finally, returned to $0 \mathrm{~mA}$ during the last six sessions.

\section{Results}

Average response rates and median durations are plotted separately for each Maudsley strain in Fig. 1. Mann-Whitney $U$ tests performed on individual S's data showed response rates for the nonreactive strain to be significantly higher than for the reactive strain during all conditions of the experiment (all ps< .05). As can be seen from Fig. 1, amount of response suppression was directly related to shock intensity for both strains of rats although both strains showed recovery of response rates under prolonged exposure to $.2 \mathrm{~mA}$ punishment. However, for each punishment intensity, the reactive strain exhibited a greater response decrement than did the nonreactive strain.

Median response duration in the absence of shock
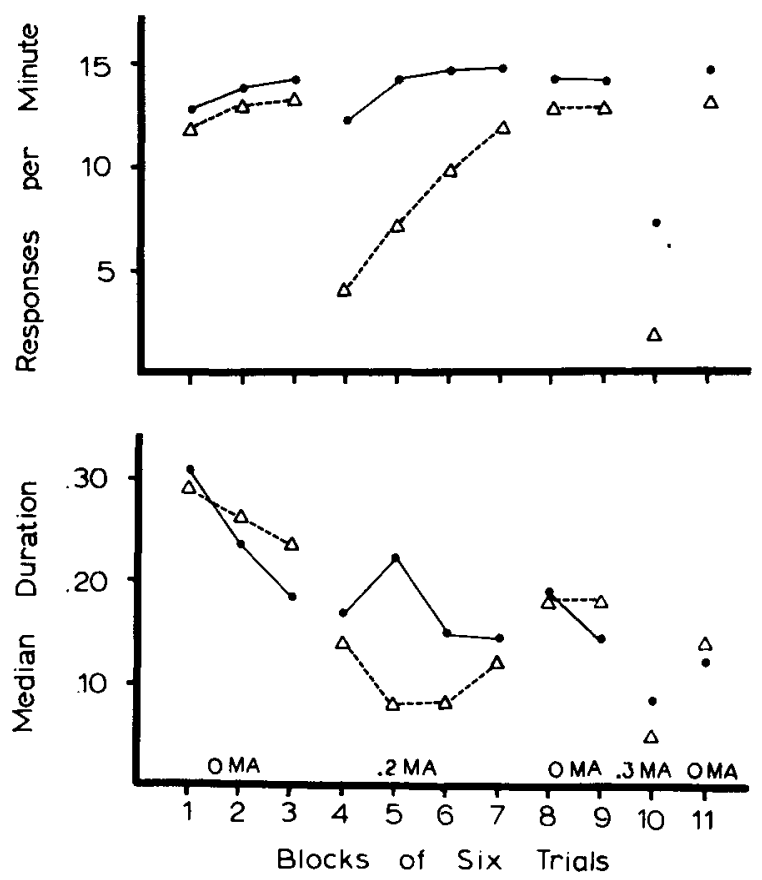

Fig. 1. Average response rate and median duration for the reactive strain (dashed line) and nonreactive strain (solid line) during each experimental condition. 
punishment was typically longer for the reactive strain than for the nonreactive strain although only the differences in medians prior to the intrcduction of .2 $\mathrm{mA}$ punishment reached significance $(p<.05)$. Responseduration dispersion or variability was also calculated for each response-duration distribution. Duration dispersion and median duration proved to be highly correlated for both the nonreactive strain ( $r h o=.87 ; \mathrm{p}<.01$ ) and for the reactive strain (rho $=.89 ; \mathrm{p}<.01$ ) using a Spearman rank-order correlation. These high correlations indicate that variability of response durations in the absence of punishment was also higher for the reactive than for the nonreactive strain. It should be noted, however, that the introduction of shock caused a greater decrease in median duration (and duration dispersion) for the reactive strain than for the nonreactive strain. Indeed, a $U$ test performed on individual S's data across both shock intensities showed that the reactive strain produced significantly shorter durations under punishment than the nonreactive strain $(p<.05)$.

\section{Discussion}

The obtained interstrain difference in response rate decrement under punishment suggests that the genetic selection procedures used to develop the Maudsley strains of rats in part determines their behavior in aversive stiuations. In this connection, the greater punishment suppression exhibited by the reactive strain provides additional support for the view that this strain has inherited a greater emotional responsiveness than the nonreactive strain (Eysenck, 1964).

The present data are consistent with the greater response decrement found for the reactive strain using a conditioned emotional response (CER) procedure (Singh, 1959) but apparently inconsistent with the established superiority of the nonreactive strain in cued-avoidance situations (Levine \& Broadhurst, 1963). To the extent that the reactive strain is more emotional, it might be expected that this strain would more rapidly acquire an avoidance response. Broadhurst \& Levine (1963) have suggested that the discrepancy between results obtained with CER and cued-avoidance procedures would be expected if the external stimulus associated with shock in each situation elicits more incompatible behavior (e.g. freezing) from the reactive than the nonreactive strain. Under the present punishment procedure, the only stimuli consistently paired with shock were those stimuli (both interoceptive and exteroceptive) produced by the lever press-release response. If the reactive strain made more incompatible (emotional) responses than the nonreactive strain to stimuli produced by the initiation of the lever response, the obtained greater punishment suppression in the reactive strain would be expected.

The significantly shorter median durations obtained here for the reactive strain under punishment suggests that the above proposed mechanism may have been operative. That is, incompatible behavior elicited by response-produced stimuli would tend to interfere with, and thus shorten, the on-going response. It should be noted, however, that punishment suppression in other strains of rats has been accompanied by an increase in response durations (Ferraro \& Hayes, 1967). Since shock was delivered through both the response lever and chamber floor, Ss received a greater amount of shock if contact was maintained with the lever than if the lever was depressed by a passing swipe at the lever. Perhaps, in the present situation, the shortening of response durations under punishment simply implicates a change in response topography from a discrete press-release response in the absence of punishment to a "swiping" response under punishment.

\section{References}

BROADHURST, P. L. Experiments in psychogenetics: Applications of biometrical genetics to the inheritance of behavior. In H. J. Eysenck (Ed.) Experiments in Personality. Vol. 1. Psychogenetics and Psychopharmacology. London: Routledge and Kegan Paul, 1960, pp. 1-102.

BROADHURST, P. L., \& LEVINE, S. Behavioural consistency in strains of rats selectively bred for emotional elimination. Brit. $J$. Psychol., 1963, 54, 121-125.

EYSENCK, H. J. (Ed.) Experiments in motivation. London: Pergamon, 1964, pp. 285-389.

FERRARO, D. P., \& HAYES, K. M. Variability of response duration during punishment. Psychol. Rep., 1967, 21, 121-127.

LEVINE, S., \& BROADHURST, P. L. Genetic and ontogenetic determinants of adult behavior in the rat. J. comp. Physiol. Psychol., 1963, $56,423-428$.

SINGH, S. D. Conditioned emotional response in the rat. 1. Constitutional and situational determinants. J. comp. Physiol. Psychol., 1959, $52,574-578$.

Notes

1. Research supported by Grant GB 5179 from the National Science Foundation to D. P. Ferraro.

2. Research carried out under National Science Foundation Grant GY 170 for undergraduate research participation. 